\title{
Eastward propagating MJO during boreal summer and Indian monsoon droughts
}

\author{
Susmitha Joseph $\cdot$ A. K. Sahai $\cdot$ B. N. Goswami
}

Received: 11 January 2008/Accepted: 16 April 2008/Published online: 30 April 2008

(C) Springer-Verlag 2008

\begin{abstract}
Improved understanding of underlying mechanism responsible for Indian summer monsoon (ISM) droughts is important due to their profound socio-economic impact over the region. While some droughts are associated with 'external forcing' such as the El-Niño and Southern Oscillation (ENSO), many ISM droughts are not related to any known 'external forcing'. Here, we unravel a fundamental dynamic process responsible for droughts arising not only from external forcing but also those associated with internal dynamics. We show that most ISM droughts are associated with at least one very long break (VLB; breaks with duration of more than 10 days) and that the processes responsible for VLBs may also be the mechanism responsible for ISM droughts. Our analysis also reveals that all extended monsoon breaks (whether co-occurred with El-Niño or not) are associated with an eastward propagating Madden-Julian Oscillation (MJO) in the equatorial Indian Ocean and western Pacific extending to the dateline and westward propagating Rossby waves between $10^{\circ}$ and $25^{\circ} \mathrm{N}$. The divergent Rossby wave associated with the dry phase of equatorial convection propagates westward towards Indian land, couple with the northward propagating dry phase and leads to the sustenance of breaks. Thus, the propensity of eastward propagating MJO during boreal summer is largely the
\end{abstract}

\footnotetext{
S. Joseph · A. K. Sahai · B. N. Goswami $(\bowtie)$

Climate and Global Modeling Division,

Indian Institute of Tropical Meteorology, Pune, India

e-mail: goswami@tropmet.res.in

S. Joseph

e-mail: susmitha@tropmet.res.in

A. K. Sahai

e-mail: sahai@tropmet.res.in
}

cause of monsoon droughts. While short breaks are not accompanied by westerly wind events (WWE) over equatorial western Pacific favorable for initiating air-sea interaction, all VLBs are accompanied by sustained WWE. The WWEs associated with all VLB during 1975-2005 initiate air-sea interaction on intraseasonal time scale, extend the warm pool eastward allowing the convectively coupled MJO to propagate further eastward and thereby sustaining the divergent circulation over India and the monsoon break. The ocean-atmosphere coupling on interannual time scale (such as El-Niño) can also produce VLB, but not necessary.

Keywords Indian summer monsoon - Droughts · El-Niño $\cdot$ MJO $\cdot$ Air-sea interaction

\section{Introduction}

Droughts and floods are extremes of monsoon interannual variability (IAV). Monsoon droughts may be defined by all India rainfall (AIR) being more than one standard deviation below long term mean and are generally of continental scale in nature (Shukla 1987; Sikka 1980; Xavier and Goswami 2007). Droughts lead to large-scale migration in search of alternative livelihoods, loss of human life due to stress, suicide, starvation or unhygienic conditions, and increased social conflict. Due to its profound impact on economy and society, the prediction of monsoon rainfall and the occurrence of drought is vital for the nation. Predictability of monsoon droughts depends on that of the monsoon IAV, which in turn depends on relative contributions of 'externally' forced to 'internally' generated components of IAV of the monsoon. Attempts to identify external factors controlling monsoon IAV has a long 
history. Following the severe drought of 1918, Sir Gilbert Walker attempted to identify several global climatic signals that are related to the Indian monsoon rainfall leading to the discovery of strong connection between the El-Niño and Southern Oscillation (ENSO) and the Indian monsoon (Walker and Bliss 1932; Walker 1933). Since then, many studies (Sikka 1980; Rasmusson and Carpenter 1982; Webster and Yang 1992; Saith and Slingo 2006) have examined in detail the association of ENSO with below normal rainfall/monsoon droughts. Between 1951 and 2004, some droughts $(1965,1968,1972,1982,1987,2002$, and 2004) co-occurred with El-Niño. During the same period, several droughts also occurred without an El-Niño (1966, 1974, and 1979). The droughts that occur in absence of an El-Niño could be due to the internal variability of the Indian summer monsoon (ISM) system, possibly through the monsoon intraseasonal oscillations (Goswami 1998; Kripalani et al. 2004). This brings us to an important question. Is there a more fundamental underlying mechanism through which droughts are produced whether they are in association with El-Niño or not? We examined the association of occurrence of monsoon droughts and length of monsoon break episodes using daily rainfall data between 1951 and 2004 (Rajeevan et al. 2006). Based on the analyses of 54 years of rainfall data, we find that about $85 \%$ of the ISM droughts between 1951 and 2004 are associated with at least one 'long break' (breaks with duration of more than 10 days; see Table 1). On the basis of observational evidences, we propose in this study that long breaks in the monsoon are responsible for ISM

Table 1 List of drought years (below 10\% of its long period average) during the period 1951-2004

\begin{tabular}{lll}
\hline Drought Years & $\begin{array}{l}\text { Long breaks identified } \\
\text { from IMD rainfall data }\end{array}$ & $\begin{array}{l}\text { Drought Years that } \\
\text { co-occurred with ENSO } \\
\text { (E)/without ENSO (NE) }\end{array}$ \\
\hline 1951 & - & - \\
1965 & $2-15$ Aug & E \\
1966 & 2-12 Jul & NE \\
1968 & 22 Aug-5 Sep & E \\
1972 & 12 Jul-4 Aug & E \\
1974 & 26 Aug-8 Sep & NE \\
1979 & 13-29 Aug & NE \\
1982 & 27 Jun-8 Jul & E \\
1985 & - & - \\
1986 & 23 Aug-8 Sep & NE \\
1987 & 16-26 Jul & E \\
2002 & $2-31$ Jul & E \\
2004 & 26 Aug-5 Sep & E
\end{tabular}

The long breaks are identified when the standardized rainfall anomalies, averaged over central India $\left(73^{\circ}-82^{\circ} \mathrm{E} ; 18^{\circ}-28^{\circ} \mathrm{N}\right)$ is below -1.0 for a duration of more than 10 days droughts. It is shown that droughts driven by external forcing (such as El-Niño) as well as those driven by internal dynamics, are all linked to 'long breaks'. Thus, long breaks may be the underlying mechanism through which monsoon droughts occur. Studies illustrate that both intraseasonal and interannual variabilities share the same spatial scale and the monsoon ISOs has the potential to influence the seasonal mean monsoon and its predictability (Goswami and AjayaMohan 2001). Therefore, understanding of the dynamics of droughts requires better understanding of 'long breaks'.

The active/break cycles of monsoon are manifestations of sub-seasonal fluctuations of the northward propagating intertropical convergence zone (ITCZ; Sikka and Gadgil 1980; Krishnamurti and Subrahmanyam 1982; see Goswami 2005 for a review). The duration and frequency of the active/break spells within a particular monsoon season contribute to the seasonal mean and thus modulates the interannual variability (Goswami and AjayaMohan 2001). Break spells are distinguished by cessation/reduction in rainfall over central and western India, with increase over foothills of Himalayas, northeast India and southeast peninsula. Break monsoon phase is more frequent in the typical monsoon months of July and August. Ramamurty (1969) noted that the duration of ISM break varies from 3-5 to 17-20 days. If the break conditions persist for a few weeks, it may lead to drought conditions.

In the past, extensive studies were carried out to propose different mechanisms that lead to the occurrence of breaks. Based on observational studies, Ramaswamy (1962) proposed that the troughs in the middle latitude westerlies can trigger breaks, by weakening the Tibetan high. He also showed that the latitudinal distance between subtropical westerly and tropical easterly jetstreams becomes shorter so that they interact with each other during breaks. Krishnamurti and Ardanuy (1980) found that break monsoon spells are associated with westward propagating trough-ridge systems (quasi-biweekly mode). The occurrence of a stagnant blocking ridge in the upper troposphere between the longitudes $90^{\circ}$ and $115^{\circ} \mathrm{E}$ over East Asia as noted by Raman and Rao (1981) can also cause monsoon breaks. Goswami and Shukla (1984) showed that breaks are integral part of monsoon ISOs that arise due to an interactive feedback between moist convection and the monsoon circulation. Supported by the atmospheric model results, Rodwell (1997) hypothesized that the breaks can be activated by the injection of dry, high negative potential vorticity air from the southern hemispheric midlatitudes. Krishnan et al. (2000) suggested that monsoon breaks are initiated by the rapid northwest propagating Rossby waves emanating from convectively stable anomalies over Bay of Bengal.

While the 'active' and 'break' spells, in general, are opposite phases of the monsoon intraseasonal oscillation 
(ISO; Goswami and Shukla 1984), a 'long break' would indicate a certain preference for the negative phase of the monsoon ISO. Not many studies have addressed the physical processes that may lead to such skewness in the monsoon ISO. In a case study on 2002 ISM drought, Krishnan et al. (2006) showed that ocean-atmosphere dynamical coupling on intraseasonal time scales, in the tropical Indian Ocean, is pivotal in forcing extended monsoon breaks and causing droughts on the subcontinent, and hence is a vital key to unlock the dynamics of monsoon droughts. Saith and Slingo (2006) also showed that air-sea interaction played an important role in causing the severe ISM drought of 2002. These case studies reveal the importance of ocean-atmosphere coupling in triggering the long breaks, thus leading to droughts. Saith and Slingo (2006) pointed out the occurrence of strong westerly wind bursts along the equator and enhancement of eastward component of Madden-Julian oscillation (MJO) during 2002. In the present study, we propose that all extended monsoon breaks between 1975 and 2005 evolved through air-sea interaction, and eastward propagating MJO in the equatorial Indian Ocean favored their sustenance, resulting in droughts. The MJO, a dominant mode of intraseasonal variability in the tropics, is a convectively coupled mode involving a Kelvin-Rossby wave couplet (Wang 2005). Wang and Rui (1990) suggested that zonal circulation horizontal gyres are important processes by which MJO shuffles mass around the tropics. MJO is prominent in the equatorial region during northern hemispheric winter. Eventhough MJO is relatively weaker and of complex structure in the boreal summer, it exists sporadically over the summer monsoon regions. The seasonality of the MJO, particularly the meridional propagation and off-equatorial behavior, may be determined by how the seasonally varying environmental conditions (the basic state and lower boundary conditions) impact the Rossby wave response (Wu et al. 2006).

Numerous investigations have been made in the past to recognize the relationship between MJO and ISM. Most of them consider ISOs associated with ISM as the poleward propagating weather anomalies of MJO; and the active/ break cycles as manifestations of these ISOs (Yasunari 1980; Madden and Julian 1971, 1972, 1994; Lau and Chan 1986; Gadgil and Asha 1992; Singh et al. 1992; KemballCook and Wang 2001; Lawrence and Webster 2002). The boreal summer ISV associated with the $30-50$ day mode is represented by the co-existence of poleward propagation of convection over the Indian and tropical Western Pacific longitudes and eastward propagation along the equator (Annamalai and Sperber 2005). Although the above investigations give some insight into the liaison between MJO and ISM, only a few researchers (e.g., Saith and Slingo 2006; Sajani et al. 2007) relate the monsoon droughts with MJO. These are, however, case studies. In an attempt to unravel the common underlying mechanism responsible for monsoon droughts, we examine all long breaks over a sufficiently long period (31 years) of data.

In this diagnostic study, we identify a relationship between an active episode of MJO during northern hemispheric summer and long monsoon break. We show that all extended monsoon breaks are associated with an eastward propagating $\mathrm{MJO}$ in the equatorial Indian Ocean and westward propagating Rossby waves between $10^{\circ}$ and $25^{\circ} \mathrm{N}$. The divergent Rossby wave associated with dry phase of equatorial convection propagates westward towards Indian land and leads to the sustenance of breaks. Thus, the propensity of eastward propagating MJO during boreal summer is essentially the cause of monsoon droughts. This hypothesis for the origin of monsoon droughts is tested from observations.

\section{Data and methodology}

In the present study, we use daily OLR measured from Advanced Very High Resolution Radiometers onboard National Oceanic and Atmospheric Administration polar orbiting spacecraft (Gruber and Kruger 1984). In the tropics, deep convection is characterized by low cloud top temperatures and small OLR values whereas shallow convection is portrayed by large OLR values. The monsoon breaks (actives) that evolve within the time scale of a few days, are characterized by suppressed (enhanced) precipitation over a wide region. As monsoon rainfall is largely convective in nature, it is credible to use the daily OLR data to spot these convection anomalies associated with the rainfall activity. The data is available globally at a resolution of $2.5^{\circ}$ longitude $\times 2.5^{\circ}$ latitude and is obtained from the website http://www.cdc.noaa.gov/of Climate Diagnostics Center (CDC), Boulder. Though the period of study is 31 years, starting from 1975 to 2005, the data for the year 1978 is not available due to some satellite problem.

OLR data is supplemented by daily surface ( $10 \mathrm{~m}$ above ground level), $850 \mathrm{hPa}$ and $200 \mathrm{hPa}$ level circulation data (both zonal and meridional) from National Center for Environmental Prediction/National Center for Atmospheric Research (NCEP/NCAR) Reanalysis (see Kalnay and coauthors 1996, available from http://www.cdc.noaa.gov/), Optimum Interpolated weekly Sea Surface Temperature (OISST) at a resolution of $1^{\circ} \times 1^{\circ}$ for the period 19822005 from ftp://ftp.emc.noaa.gov (Reynolds et al. 2002), 40-year ECMWF Re-Analysis (ERA-40) $850 \mathrm{hPa}$ zonal wind for the period $1975-2001$ at $2.5^{\circ} \times 2.5^{\circ}$ resolution (source: http://data.ecmwf.int; Uppala et al. 2005) and NOAA Extended Reconstructed monthly Sea Surface 
Temperature (ERSST) at a resolution of $2^{\circ} \times 2^{\circ}$ for the period 1977-2006 (Smith and Reynolds 2004). High resolution $\left(1^{\circ} \times 1^{\circ}\right)$ gridded daily rainfall data from National Climate Centre (NCC), India Meteorological Department (IMD), Pune (Rajeevan et al. 2006) for the same period is also used. The gridded rainfall data for the Indian region from IMD is made by analyzing quality controlled daily rainfall data over 1,803 stations distributed over the country.

The first part of our analysis aims at categorizing breaks into 'short' and 'long' breaks and to identify certain characteristic differences between them in terms of propagation characteristics and association with other parameters. For this purpose, the following steps are carried out: (1) identification of active and break spells in the Indian summer monsoon season and classifying them into short and long spells based on their duration, (2) composite analysis of the spatial distribution of OLR, SST and circulation anomalies for very short and very long break spells separately, (3) the assessment of propagation characteristics of tropical convection and (4) wavenumberfrequency spectrum analysis to identify the dominant modes and their propagation characteristics.

\subsection{Identification procedure}

As high OLR values represent suppressed convection and low OLR values represent increased convection, the break (active) spells constitute consecutive days having high (low) OLR values. The procedure of identification is delineated below.

- Using 31 year (1975-2005) of daily OLR data, a daily climatological OLR time series, is constructed and daily anomalies during each year are computed. These anomalies are then standardized by normalizing them by their own standard deviation.

- The identification is done from 10 June to 15 September, with the view that early June and late September are not suitable for inferring breaks. Delayed onset and early withdrawal of monsoon can lead to the misinterpretation of breaks (Krishnan et al. 2000). Hence identifying these spells from 10 June to 15 September for each year is reasonable.

- Significant reduction of rainfall over the central India is a characteristic feature of the breaks. Hence, we selected the area $73^{\circ}-82^{\circ} \mathrm{E} ; 18^{\circ}-28^{\circ} \mathrm{N}$, representing the central India, for crafting the criteria for identifying the breaks. Breaks are identified when the standardized OLR anomaly averaged over this region is more than 0.9 for consecutive 4 days and the average anomaly over the region during the period exceeds 1.0. Based on the duration, they are classified as very long (duration of more than 10 days), long (greater than 1 week and less than or equal to 10 days), short (less than or equal to 1 week) and very short (4-5 days). Here, we give emphasis on the very long and very short breaks (hereafter referred to as VLB and VSB, respectively), with the presumption that different mechanisms generate them.

\section{Results and discussions}

As long breaks seem to be the common seminal factor for all droughts, the skill in prediction of droughts may be advanced by better understanding of dynamics of long breaks. In order to gain insight into factors responsible for them, we examine here the spatial structure and propagation of climate anomalies associated with VLB and compare them with those associated with VSB. Using the criterion discussed in the previous section, a total of 41 break spells and 348 break days are identified. In concurrence with the observations, majority of breaks are found in the months of July and August. The break spells identified in the present study are comparable with those identified by Gadgil and Joseph (2003) and Rajeevan et al. (2006). Ten cases of VLB and 11 cases of VSB have been identified for the study period (Table 2). It may be noted that all the drought years during this period, with the exception of 1985 are associated with long breaks, supporting our argument. However, it may also be noted that a few VLB do occur during non drought years as well $(1992,1997)$.

\subsection{OLR break anomalies}

As discussed earlier, the geographical/spatial distribution of OLR anomalies provides an insight into the association

Table 2 List of long and short breaks identified using the proposed criteria for the period 1975-2005

\begin{tabular}{ll}
\hline Long breaks & Short breaks \\
\hline 1979: 10-28 Aug (19) & 1985: 29 Jun-3 Jul (5) \\
1982: 25 Jun-7 Jul (13) & 1985: 23-26 Aug (4) \\
1983: 4-14 Jul (11) & 1985: 6-9 Sep (4) \\
1986: 21 Aug-8 Sep (19) & 1989: 31 Jul-4 Aug (5) \\
1987: 14 Jul-3 Aug (21) & 1993: 19-22 Jun (4) \\
1992: 24 Jun-9 Jul (16) & 1995: 2-5 Jul (4) \\
1997: 2-17 Aug (16) & 1995: 13-17 Aug (5) \\
2002: 3-16 July (14) & 1999: 28 Jun-1 Jul (4) \\
2004: 20 Jun-1 Jul (12) & 2000: 10-13 Sep (4) \\
2004: 23 Aug-2 Sep (11) & 2004: 9-12 Jul (4) \\
& 2004: 18-22 Jul (5) \\
\hline
\end{tabular}

Number of days in each break spell is indicated in the brackets 
of regional anomalies during break or active spells with the global features. Compositing the OLR anomalies of 31 years helped us to objectively determine both the structure and amplitude of convection anomalies during ISM breaks. Figure 1a and $\mathrm{b}$ demonstrate the composite OLR anomalies during VLB and VSB, respectively.

VLBs are characterized by organized suppressed convection in a northwest-southeast oriented band extending from continental India to the maritime continents. The presence of positive OLR anomalies over Indian region and maritime continents and negative anomalies over eastern equatorial Indian Ocean and over China and Japan is wellknown as the "quadruplet" structure (Krishnan et al. 2000; Annamalai and Slingo 2001; Annamalai and Sperber 2005). This quadruplet structure is clearly evident in the VLB composite (Fig.1a), whilst the large scale organized structure of the positive OLR anomalies is absent in the VSB composite (Fig.1b) and is characterized by active convection over Indonesia, south China Sea and north Bay of Bengal.

Another significant feature that differentiates a VLB from a VSB is the presence of strong negative OLR anomalies over equatorial eastern and central Pacific Ocean, a feature characteristic of El-Niño conditions, concurrent with the suppressed convection over Indian region. This strong negative anomaly is replaced by strong positive anomalies in the VSB composite. Another notable characteristic is the presence of negative anomalies in the equatorial Indian Ocean. The negative anomaly which was confined in the eastern equatorial Indian Ocean region in the VLB composite is seen to be spread in to the Bay of Bengal and western Indian Ocean in the VSB composite. In the VLB composite, there is a symmetric pattern of suppressed and enhanced convection along the equator, which may indicate a Kelvin wave dynamics. The tilting of suppressed convection from the maritime continents towards Indian region may be due to Rossby wave dynamics, as suggested in earlier studies (Krishnan et al. 2000)

\subsection{Circulation anomalies}

Wind anomalies at $200 \mathrm{hPa}, 850 \mathrm{hPa}$ and at surface composited for VLB and VSB from NCEP are shown in Fig.2. Figure $2 \mathrm{a}$ and $\mathrm{b}$ show the spatial distribution of circulation anomalies at upper troposphere (200 hPa) during VLB and $\mathrm{VSB}$, respectively. The presence of strong westerly anomalies over India during both VLB and VSB is due to the weakening of TEJ. Another salient feature to be noted is the eastward shift in the position of the Tibetan high. The weakening and shift of the Tibetan high during inactive periods of monsoon has already been established by earlier studies (Ramaswamy 1962; Raman and Rao 1981). During a VLB, a pair of anomalous anticyclone may be seen straddling the equator over eastern and central Pacific (Fig.2a). This is in concurrence with the increased convection present over this region (Fig. 1a). Consistent with
Fig. 1 Composite OLR anomaly in $\mathrm{Wm}^{-2}$ during, a VLB and $\mathbf{b}$ VSB, for the period 1975-2005

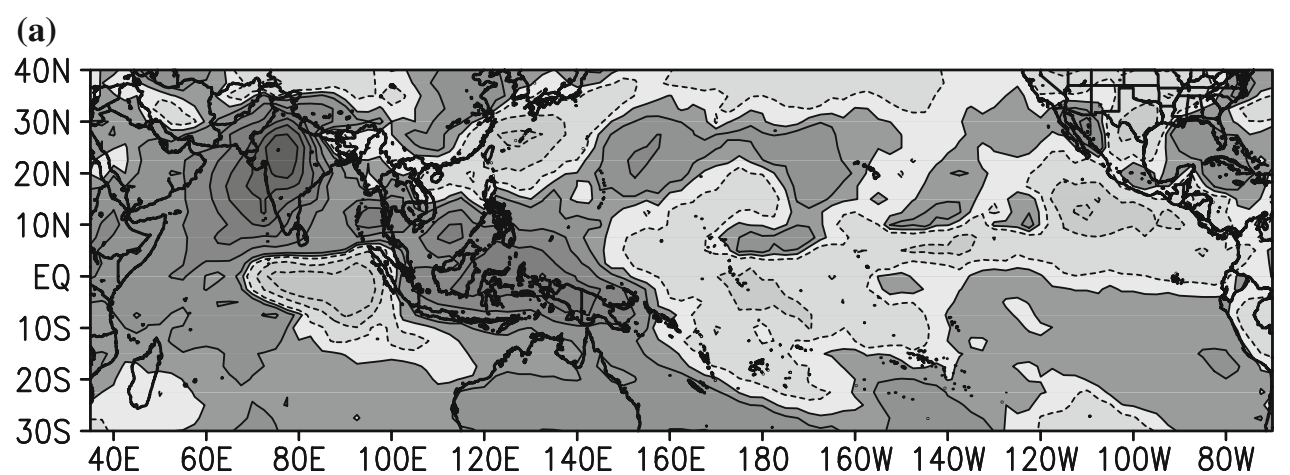

(b)

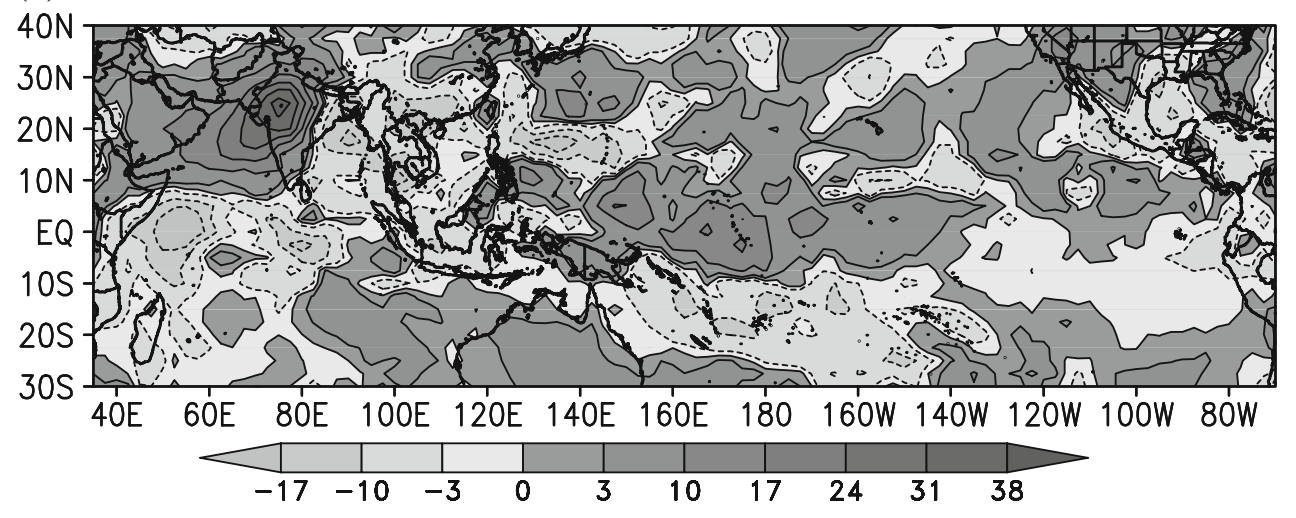


(a)

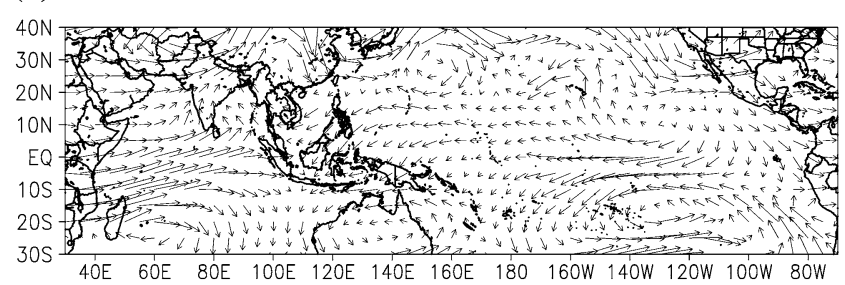

10

(b)

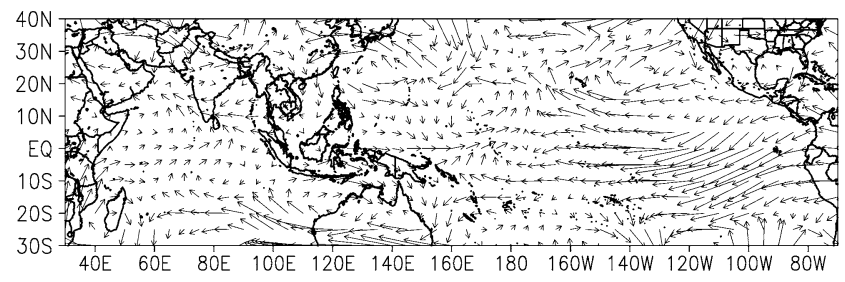

10

(c)

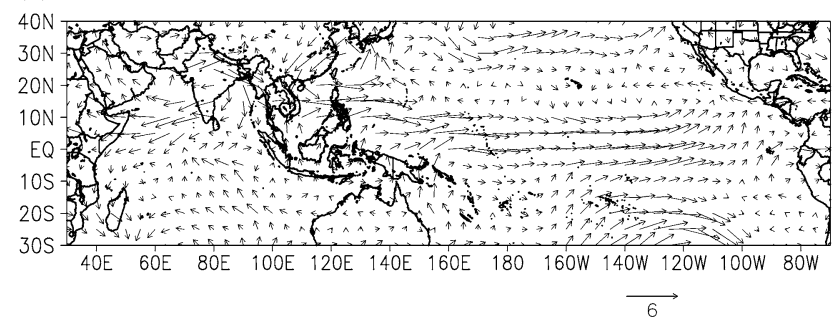

(d)

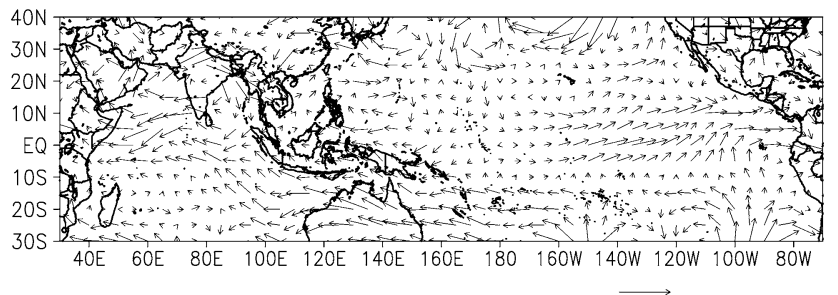

(e)

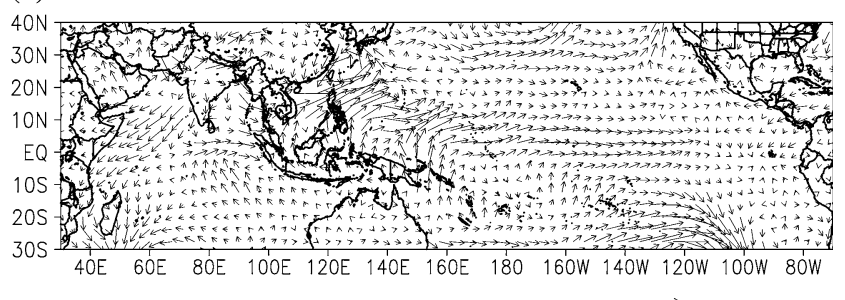

(f)

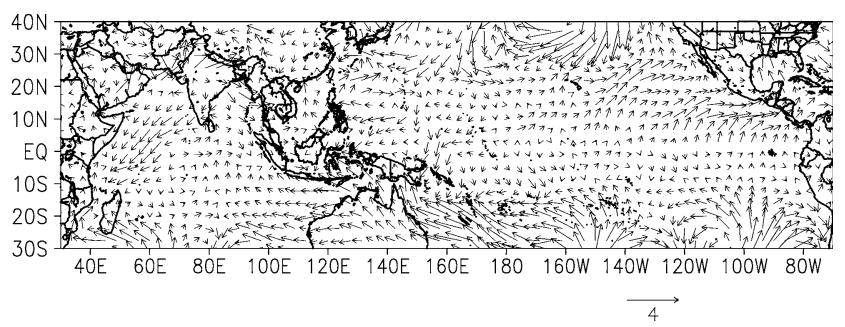

Fig. 2 Circulation anomalies in $\mathrm{ms}^{-1}$ at $200 \mathrm{hPa}$ during a VLB, b VSB Circulation anomalies in $\mathrm{ms}^{-1}$ at $850 \mathrm{hPa}$ during c VLB, d VSB. Circulation anomalies in $\mathrm{ms}^{-1}$ at surface at $10 \mathrm{~m}$ height during e VLB, f VSB

lack of organized equatorial convection during a VSB composite (Fig.1b), only an anomalous anticyclonic circulation in the northeastern Pacific is seen (Fig.2b). Also, the anomalous anticyclonic circulation in the northern hemispheric central Pacific during VLB is replaced by an anomalous cyclonic circulation in the VSB composite.

The common features noted at $850 \mathrm{hPa}$ during VLB as well as VSB (Fig. 2c, d) are the general weakening of the summer monsoon flow and the presence of an anomalous anticyclonic circulation over India; anomalous low level easterlies over Arabian Sea, and a cyclonic regime over north western Pacific Ocean, eastern China and southern Japan. The anomalous easterlies over Arabian Sea and anomalous anticyclonic wind anomalies over India are indicative of major reduction in the moisture transport from Arabian Sea to the Indian region (Krishnan et al. 2000). The anomalous cyclonic anomalies over northwestern Pacific region are suggestive of the increased typhoon activity over this region. Some recent studies (Mujumdar et al. 2006) show that increased typhoon activity over this region can cause anomalous subsidence over Indian region leading to monsoon breaks. An important characteristic that distinguishes the VLB from VSB is the strong westerly anomaly at $850 \mathrm{hPa}$ across the length of the equatorial
Pacific in the case of VLB as compared to the composite of VSB where they are confined to the eastern Pacific only (see Fig. 2d). Most of the features noted at the $850 \mathrm{hPa}$ level during both VLB and VSB composites are more clearly evident in the surface winds (Fig. 2e, f).

Among the above said features, the most important one to be noted during VLB is the strong low level westerly wind anomalies prevailing in the western equatorial Pacific, which is absent during VSB (as seen in Fig. 2c, d). Such strong low level winds in the western part of Pacific can trigger equatorial jets and Kelvin waves in the ocean that may influence air-sea interactions in the region. To illustrate this further, we made composite of ERA-40 zonal wind anomalies at $850 \mathrm{hPa}$, averaged over the region $150^{\circ}-$ $170^{\circ} \mathrm{E} ; 5^{\circ} \mathrm{S}-5^{\circ} \mathrm{N}$. Taking the starting date of the breaks as reference point, the composite zonal wind anomalies from 15 days prior to and 15 days after the reference point have been made for both VLB and VSB (Fig. 3a, b). It may be noted that the initiation of a VLB is preceded by persistent westerly wind anomalies in the western equatorial Pacific for over 15 days together with a burst of westerly winds during the time of initiation of VLB spells. These westerly wind events (WWEs) are considered to be surface signature of MJO and are responsible for the extension of warm 
Fig. 3 Composite zonal wind anomalies in $\mathrm{ms}^{-1}$ averaged over $150^{\circ}-170^{\circ} \mathrm{E} ; 5^{\circ} \mathrm{S}-5^{\circ} \mathrm{N}$ during $\mathbf{a}$ VLB and $\mathbf{b}$ VSB. Here, zeroth day is the starting date of break spells (a)

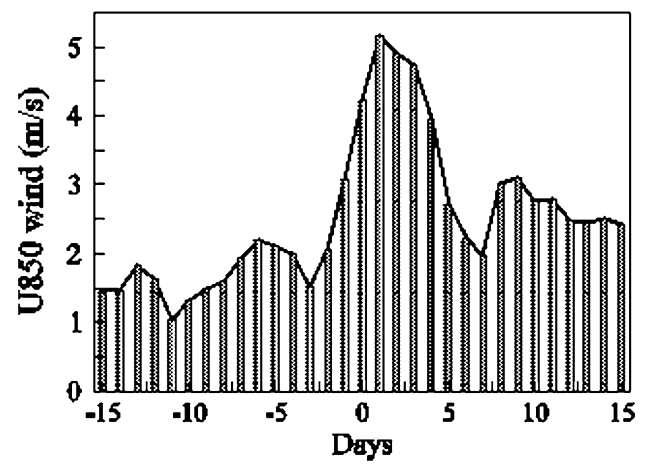

(b)

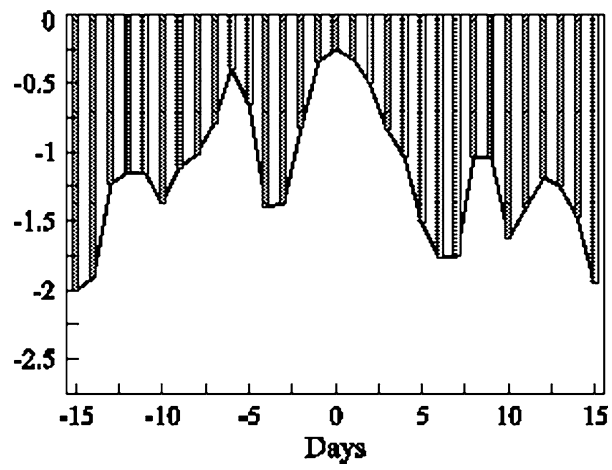

SST anomalies to the central Pacific (Saith and Slingo 2006; Wang 2005). During VSB, the mean easterlies are strengthened (as seen from the easterly anomalies) over the region (Fig. 3b) and hence the eastward extension of the warm pool is inhibited.

\subsection{Propagation of OLR anomalies}

The circulation anomalies during VLB are indicative of presence of Kelvin-Rossby wave in the equatorial Indian Ocean and western Pacific which is conspicuous by its absence during VSB. This is further illustrated by making the phase composite of OLR anomalies. Taking the beginning of the breaks as reference point, phase composite of
OLR anomalies from 30 days prior to and 30 days after the reference point have been made for VLB as well as VSB. Figure 4a shows the longitudinal distribution of the movement of composite OLR anomalies averaged over the equatorial region $\left(5^{\circ} \mathrm{S}-5^{\circ} \mathrm{N}\right)$, during the VLB. The presence of a strong eastward propagating wave is clearly seen in the VLB composite, which is absent during VSB spells (Fig. 5a). The identified wave is having wave number 4 and velocity of about $5 \mathrm{~m} / \mathrm{s}$, which is similar to that of MJO. This feature is clearly visible in the 20-80 day filtered anomalies (filtered using Lanczos filter; Duchon 1979) also (Figure not shown). When averaged over the region $10^{\circ}-25^{\circ} \mathrm{N}$, the composite VLB anomalies show a westward propagation (Fig. 4b). The suppressed convection over the
Fig. 4 Propagation characteristics of typical VLB a time-longitude plot of composite OLR anomalies in $\mathrm{Wm}^{-2}$ averaged between $5^{\circ} \mathrm{S}$ and $5^{\circ} \mathrm{N}$, b same as (a), but for $10^{\circ}-25^{\circ} \mathrm{N}$, c time-latitude plot of composite OLR anomalies in $\mathrm{Wm}^{-2}$ averaged over $70^{\circ}-90^{\circ} \mathrm{E}$
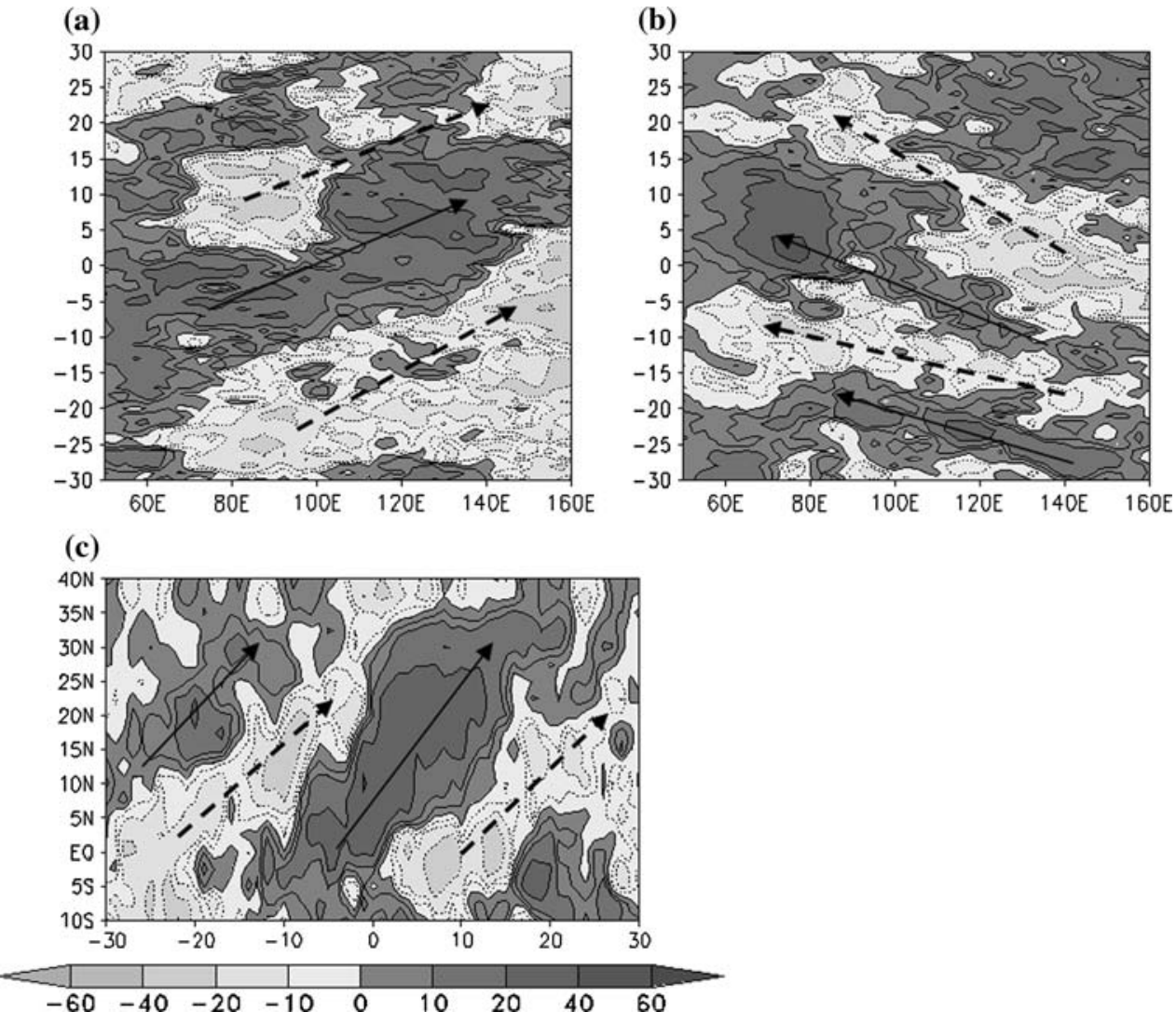
Fig. 5 Same as Fig. 4, but for VSB
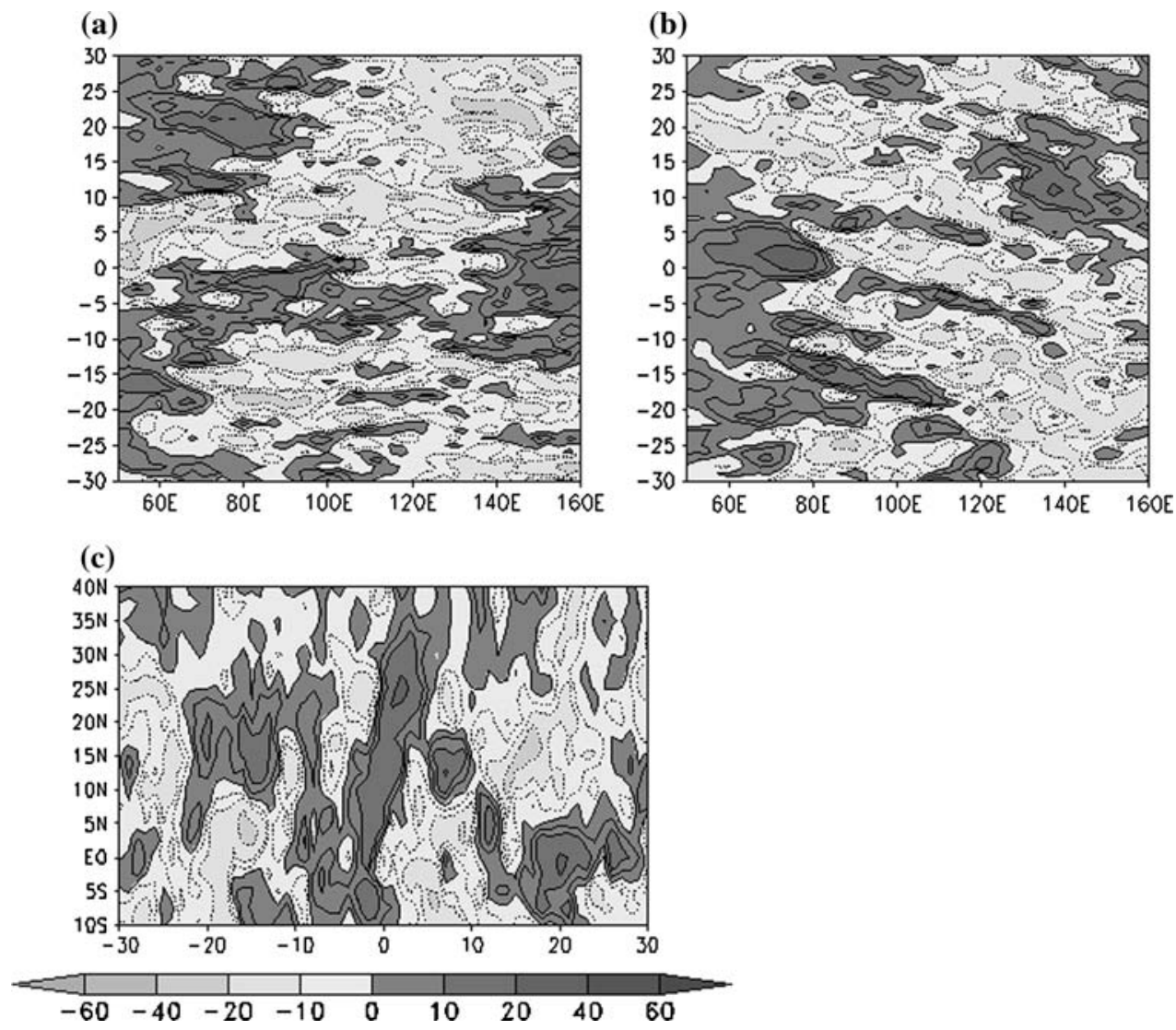

Indian subcontinent during VLB could be linked to westward propagating suppressed convection anomaly in the western Pacific 10-15 days earlier. During VSB no clear eastward propagation along equator or westward propagation between $10^{\circ}$ and $25^{\circ} \mathrm{N}$ could be seen (Fig. 5a, b). In particular, the suppressed convection over India during such breaks is not linked to any organized suppressed convection in the western Pacific (Figs. 1b, 5b). Similarly the latitudetime cross-section of the composite VLB anomalies averaged over the longitudes $70^{\circ}-90^{\circ} \mathrm{E}$, (Fig. 4c), depicts well organized northward movement of suppressed convection anomalies, whereas the movement is not well organized in the case of VSB composite (Fig. 5c). An examination of the two composites (Figs. 4, 5) indicates that the VLBs and VSBs are associated with the lower frequency (40-60 days) and the higher frequency (15 day mode) components of the monsoon ISO, respectively.

From the above analysis, it is seen that sustained breaks are associated with eastward propagating events in the equatorial waveguide that propagates to the Central Pacific. The slow propagation is due to strong convective coupling over warm waters and the extension of propagation to Central Pacific is due to eastward extension of the warm pool in the Pacific. Our analysis indicates that the eastward propagating events generates westward moving Rossby wave between $10^{\circ}$ and $25^{\circ} \mathrm{N}$ similar to the ones discussed in some earlier studies (Rui and Wang 1990; Krishnan et al. 2000; Kemball-Cook and Wang 2001) and leads to sustained breaks.

\subsection{Wavenumber-frequency spectra}

We have noted that most of the drought years occur in concurrence with VLB and strong eastward propagation is present in the equatorial Indian Ocean, during long breaks. What are these eastward propagating intraseasonal oscillations? It is proposed that they are the eastward propagating MJO. Thus, drought years should show a higher propensity of MJO during northern summer. To support this hypothesis, a wavenumber-frequency spectrum analysis is carried out over the latitudinal band $15^{\circ} \mathrm{S}-15^{\circ} \mathrm{N}$ to bring out the dominant mode during three flood years $(1983,1988$, and 1994) and seven drought years $(1979,1982,1985,1986$, 1987,2002 , and 2004) within the study period. The analysis is done for two seasons: the northern hemispheric summer (May-October) and winter (November-April).

\subsubsection{Space-time OLR spectra during winter, summer, drought and flood}

The feature with maximum power is the MJO, occurring mostly in the wavenumbers 1,2 , and 3 and centered at a 
period of about 40-50 days, in all the four cases-winter, summer, drought and flood (Figure not shown). The significant peaks obtained match very well with that explained by Wheeler and Kiladis (1999), even though they used overlapping 96 day segments whereas the present study makes use of non-overlapping 184 day segments. The interesting feature to be noted is that greatest significance is seen for the lower wavenumbers and longer periods in the symmetric component of OLR (OLRS). During northern summer, increased power occurs at westward wavenumbers of about 6-14 and at periods around 2.510 days for both OLRA (asymmetric component of OLR) and OLRS, which is absent during northern winter. This increased power is due to the predominance of tropical depressions (TD) type disturbances during the summer (Wheeler and Kiladis 1999; Dunkerton and Baldwin 1995). The presence of such disturbances in both OLRA and OLRS is because of the fact they form only on one side of the equator. Even though the magnitude is somewhat reduced in the northern summer, MJO is present in both the seasons, consistent with the earlier studies (Madden and Julian 1994; Salby and Hendon 1994; Wheeler and Kiladis 1999). If we take the difference of OLRS in winter and summer, we can clearly see that stronger MJO is present during winter compared to summer (figure not shown). It is found that summers of drought years are like winter season in general when there exists a stronger eastward propagating $\mathrm{MJO}$ in the equatorial region in contrast to much weaker eastward propagating component during summers of flood years supporting our claim made in the earlier section.

\subsubsection{Power distribution over wavenumbers and periods}

As the MJO occurs in the range of wavenumbers 1-4, we examine eastward and westward propagating power in the OLRS spectra averaged over wavenumbers $1-4$ during all winters and all summers and during summers of drought years and flood years. Consistent with some earlier findings, the MJO in the range of periods between 10 and 60 days is much stronger in winter than in summer. Further, the eastward propagating component is much stronger than the westward propagating component during winter compared to that in summer (Fig.6a, b). Within the summer season, the contrast between powers of MJO during drought years compared to flood years is similar to that between winter and summer. During drought years, not only the power is higher in the period range between 30 and 60 days compared to those in flood years, the eastward power clearly dominates over the westward propagating power giving the MJO a clear eastward propagating character (Fig. 6c, d). Further, during flood years westward propagating power even dominates over that for eastward propagating component for the period range between 45 and 60 days (Fig.6d). On the other hand, the amplitude and frequency of the higher frequency component of summer ISO (with periods between 10 and 20 days) remains comparable during both flood and drought years (Fig.6c,
Fig. 6 Power of symmetric OLR spectrum averaged over the wavenumber range $1-4$ for a winter, $\mathbf{b}$ summer, $\mathbf{c}$ drought and d flood (a)

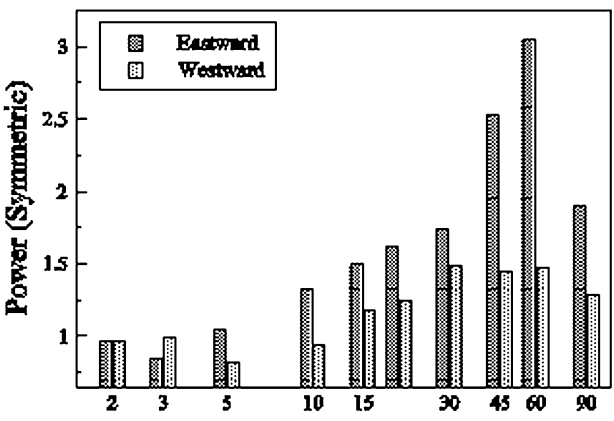

(c)

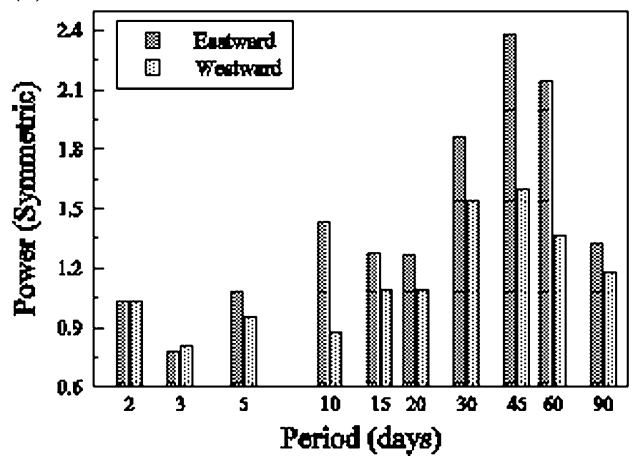

(b)

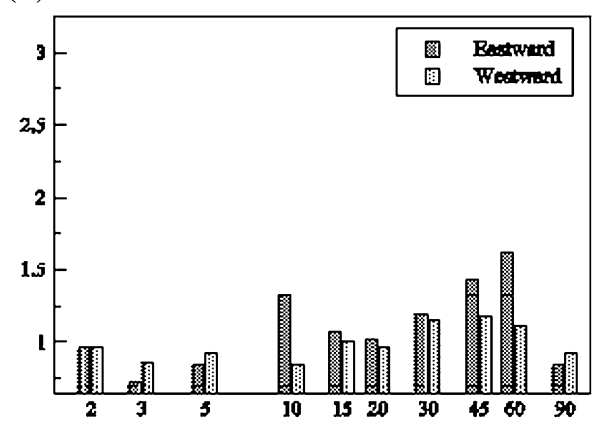

(d)

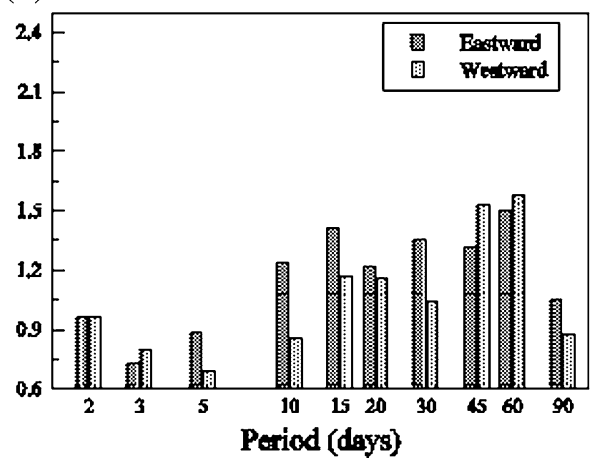


d). This is consistent with the fact that the VLBs are associated with the lower frequency component of summer ISO (Fig.4) and are responsible for the monsoon droughts.

Since MJO appears within a period of 30-60 days, the power in the OLRS spectra during this period range is averaged for all the cases, to see in which wavenumber it contributes more and to find out whether eastward or westward power is overriding. For winter and summer, the maximum power appears at wavenumber 1 . In the case of drought, the maximum power lies at eastward wavenumber 1 , while for flood maximum power is in the westward wavenumber 4 . At both wavenumber 1 and 2, the eastward powers dominate the westward one. For flood, westward power takes over eastward one at wavenumber 2 . If we see the ratio of eastward power to the westward power, in all the cases, the ratio is more than 1 at wavenumber 1 . For winter, the ratio is more than 3 at wavenumber 1 , whilst it is about only 2.3 in the case of summer (figure not shown). The ratio is 2.6 for drought and about 1.95 for flood. At wavenumber 5 , the ratio is about 1.7 in the case of flood, which is a unique characteristic (Fig. 7c, d).

\subsection{Air-sea interaction and long breaks}

There are some indication that air-sea interaction may lead to extended breaks and a monsoon drought (Saith and Slingo 2006; Krishnan et al. 2006). Saith and Slingo (2006) indicated that the westerly wind burst in the western Pacific associated with the MJO leads to extension of warm SST anomalies to the east, initiating an El-Niño, creating a long break over Indian region and a monsoon drought. These studies are case studies of monsoon drought 2002 which was associated with an El-Niño. However, there are many droughts that are not associated with an El-Niño. Here, we have shown that almost all droughts are associated with VLB. In this section, we show that all VLBs whether associated with an El-Niño or not are due to air-sea interactions similar to that described by Saith and Slingo (2006).

Kumar et al. (2006) showed that the two "flavors" of El-Niño (hereafter termed as Type I El-Niño when warm SST anomalies are centered in the eastern Pacific and Type II El-Niño when they are centered in the central Pacific) can result in significantly different responses in the Indian monsoon. They also showed that India is more prone to drought when the ocean warming signature of El-Niño extends westward. Based on the Empirical Orthogonal Function (EOF) analysis carried on the JJAS mean of ERSST data from 1977 to 2006 (Fig. 8), we identify that out of the 10 VLBs identified, four co-occurred with Type I El-Niño cases (1982, 1983, 1987, and 1997), three with Type II El-Niño cases (2002 and 2004; out of the three cases, two VLB emerged in 2004) and three with non El-Niño cases (1979, 1986, and 1992). We agree with the general premise put forward by Saith and Slingo (2006), but feel that it need not be restricted to El-Niño years only. VLB composite of actual OISST during Type-I El-Niño events, Type-II El-Niño years and non El-Niño years (here
Fig. 7 Power of symmetric OLR spectrum averaged over the period 30-60 days for a winter, b summer, c drought and d flood (a)

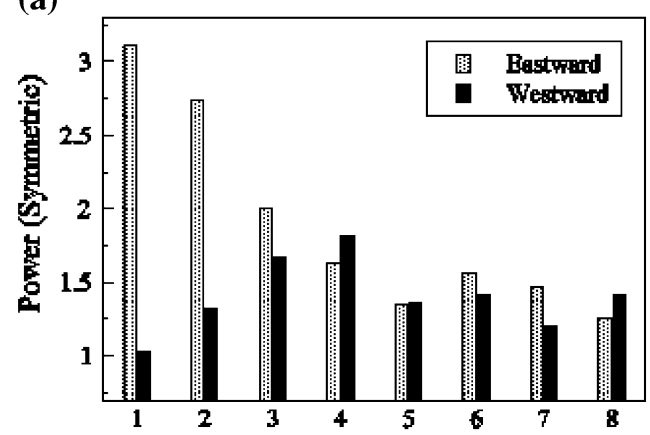

(c)

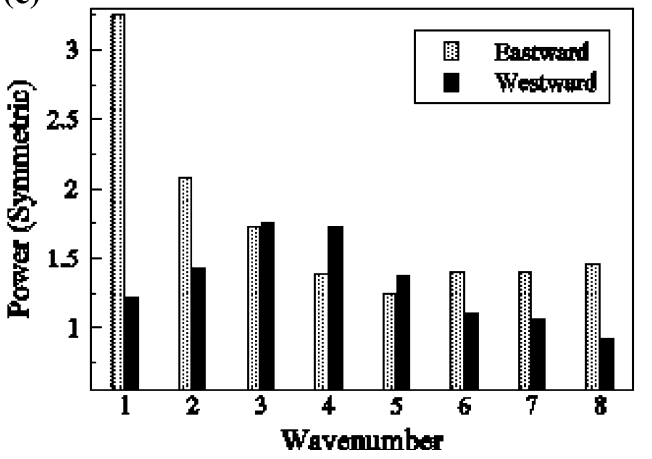

(b)

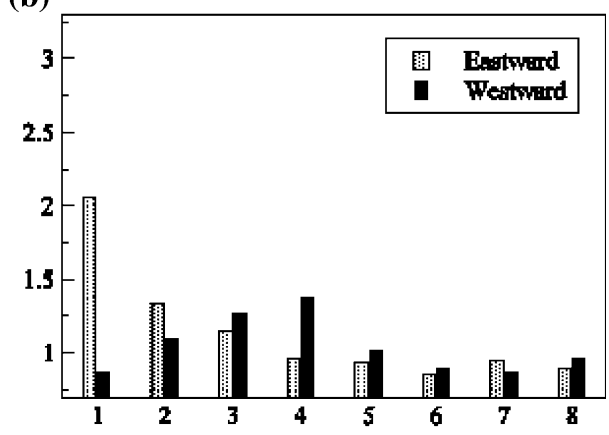

(d)

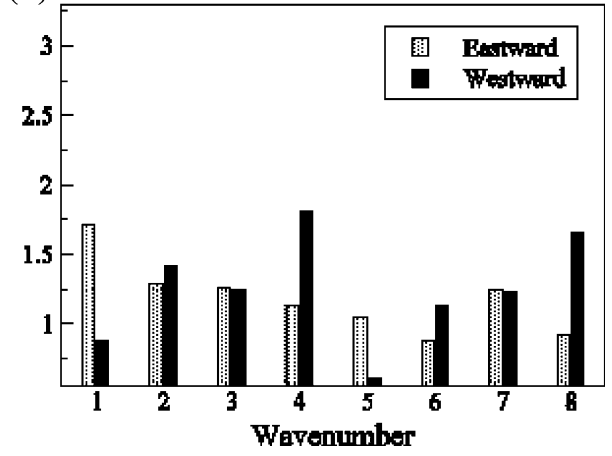


Fig. 8 The dominant modes of Pacific Ocean Variability during JJAS identified from ERSST data for a EOF1, b EOF2 and c the interannual variability of $\mathrm{PC} 1$ and $\mathrm{PC} 2$ during the period 1977-2006

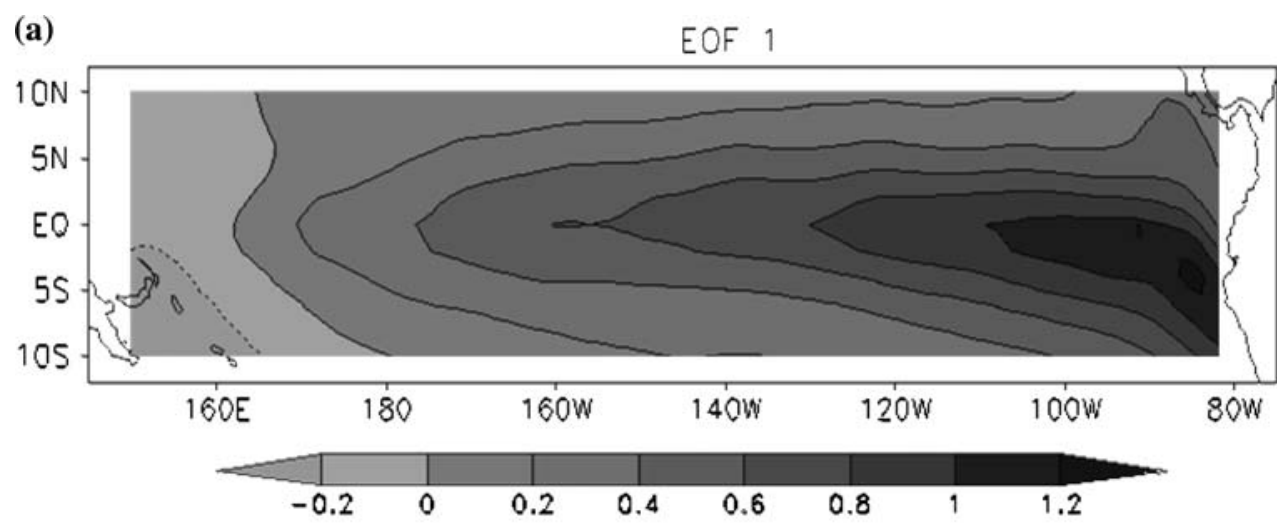

(b)

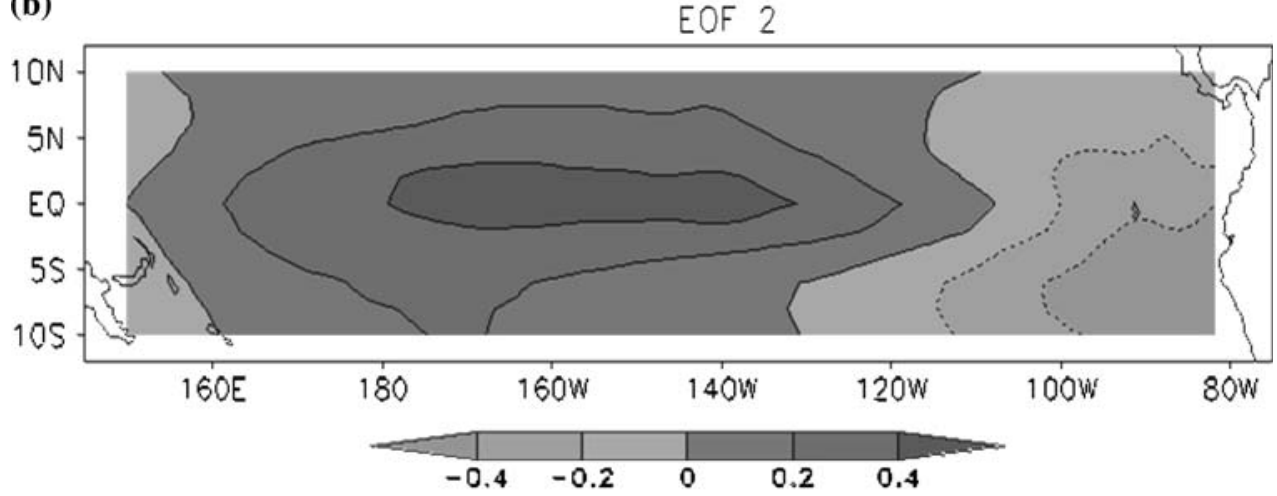

(c)

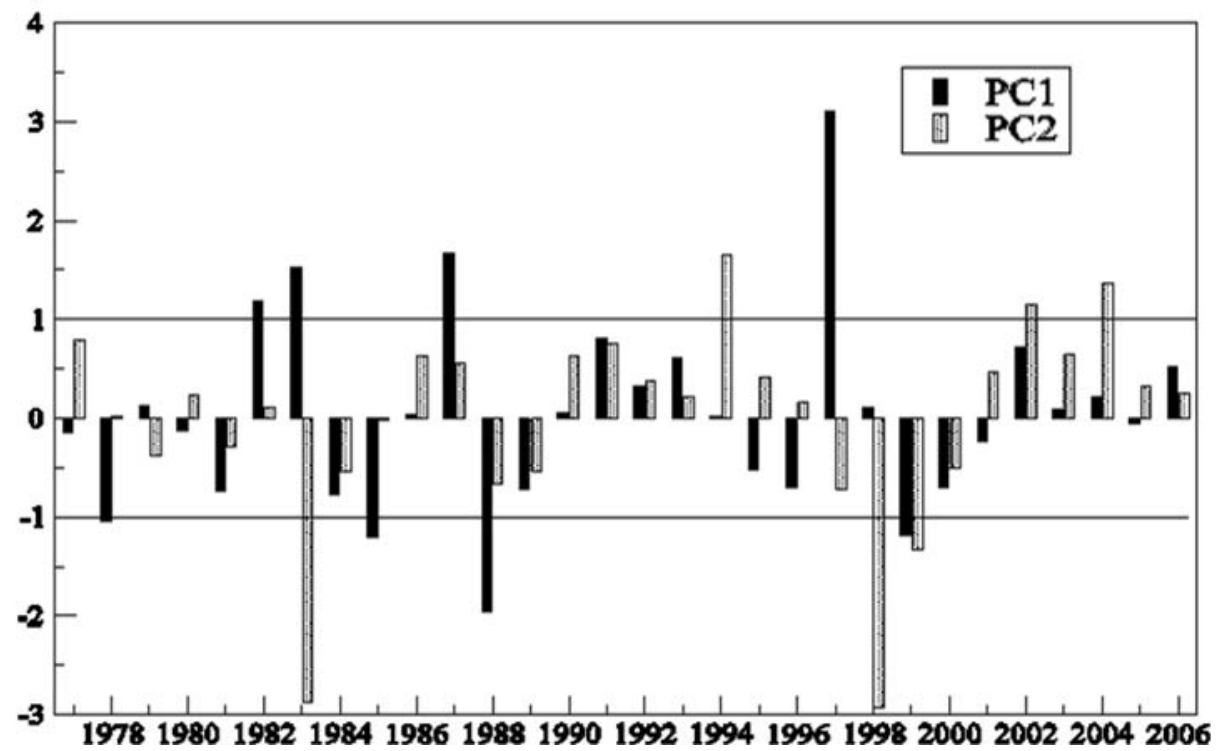

1979 is excluded as OISST data is from 1982 onwards and no weekly or daily SST data is available for 1979) shows that the warm pool of western Pacific has extended to the central and eastern Pacific, during all the three cases (Fig. 9). We note that warm SST anomalies prevail over equatorial central Pacific, irrespective of El-Niño and non El-Niño years (figure not shown). These warm SST anomalies generate atmospheric responses in both intraseasonal and interannual time scales and is responsible for the extended eastward propagation of MJO, leading to long breaks and hence droughts. The warm SST anomalies exist almost all over the equatorial Indian Ocean, as explained by Krishnan et al. (2003), particularly in the non El-Niño years. We feel that air-sea interaction on the interannual time scale may be important in the El-Niño years, whereas in the non El-Niño years, ocean-atmosphere coupling on the intraseasonal scale is imperative. This becomes clearer in the NCEP zonal wind VLB composite at $850 \mathrm{hPa}$ level, 
Fig. 9 VLB composite of actual OISST in degree Celsius during a Type-I El-Niño events (1982, 1983, 1987, and 1997), b Type-II El-Niño years (2002 and 2004), c non El-Niño years (1986 and 1992). The $28.5^{\circ} \mathrm{C}$ isotherm of JJAS mean OISST is marked as dashed line

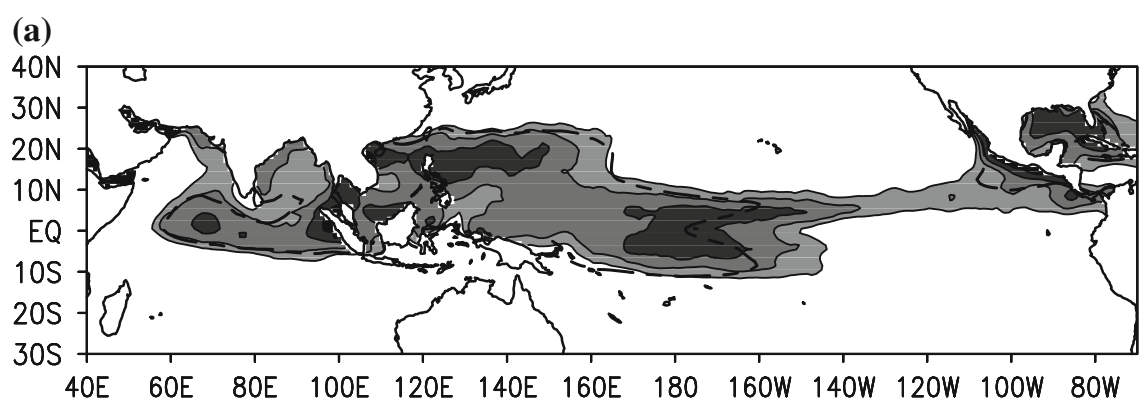

30

(b)

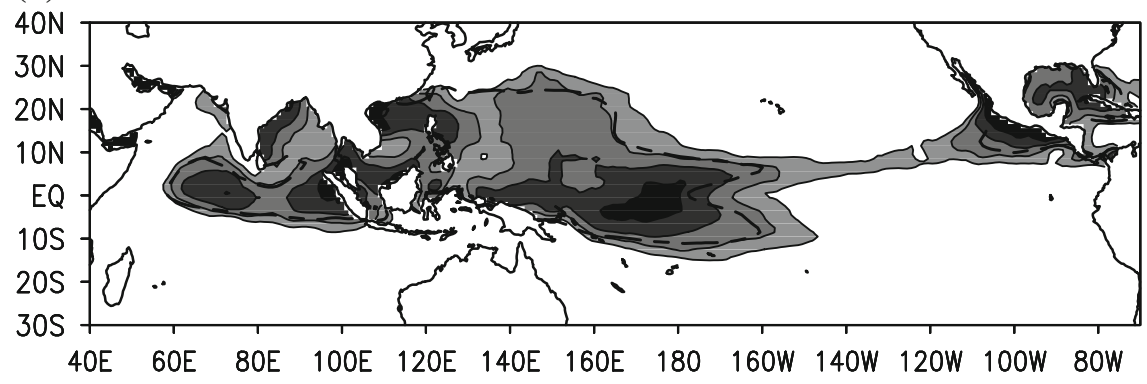

29.5

(c)

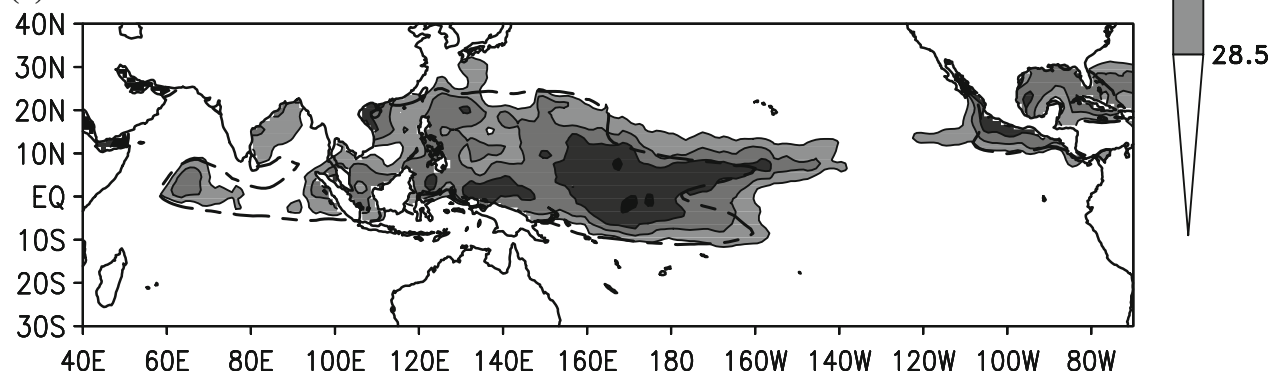

averaged over the region $150^{\circ}-170^{\circ} \mathrm{E} ; 5^{\circ} \mathrm{S}-5^{\circ} \mathrm{N}$, for the period 1975-2005. The zonal wind composite is made separately for Type I, Type II and non El-Niño cases (Fig. 10). During both type of El-Niño cases, the westerly wind anomalies persevere for about 10-15 days after the initiation of the break spells. In non El-Niño cases, the westerly wind anomalies are present, but they are relatively short lived and are of lesser magnitude. However, they are still responsible for producing the extension of warm pool even in this case (Fig.9c), albeit of slightly smaller extent. This, however, seems to be adequate in extending the eastward propagation of the MJO to the Central Pacific and causing an extended monsoon break.

\section{Concluding remarks}

In this study, we unravel a fundamental dynamical process that is responsible for not only those droughts associated with external forcing (e.g., El-Niño) but also those generated by internal dynamics. Analyses reveal that almost all ISM droughts are associated with at least one VLB (breaks with duration of more than 10 days). However, few VLBs are found during non drought years as well. As almost all drought years are associated with VLB, we propose that VLB may be the underlying factor that gives rise to droughts, and believe that understanding of the dynamics of droughts is mostly related to understanding of the dynamics of 'long breaks'.

With the conjecture that different mechanisms are responsible for VLB and VSB, the spatial distribution of climate anomalies during VLB as well as VSB is examined and compared with each other. Although we used only OLR data to identify the breaks, there is consistency between the composited OLR and circulation anomalies. During VLB, strong low level westerlies are prevalent in the western equatorial Pacific. Such westerly wind events (WWEs) are normally associated with MJO and can trigger Kelvin waves in the ocean, influencing the evolution of El-Niño conditions. In the OLR composite of VLB, there is a symmetric pattern of suppressed and enhanced convection along the equator. This indicates a Kelvin wave dynamics. The composite OLR anomalies during VLB averaged over $5^{\circ} \mathrm{S}$ and $5^{\circ} \mathrm{N}$ reveal the presence of a strong eastward propagating wave, similar to MJO. When averaged over $10^{\circ}-25^{\circ} \mathrm{N}$, the VLB anomalies show a westward 
Fig. 10 VLB composite of NCEP zonal wind anomalies in $\mathrm{ms}^{-1}$ during a Type-I El-Niño events (1982, 1983, 1987, and 1997). b Type-II El-Niño years (2002 and 2004), c non El-Niño years $(1979,1986$, and 1992) (a)
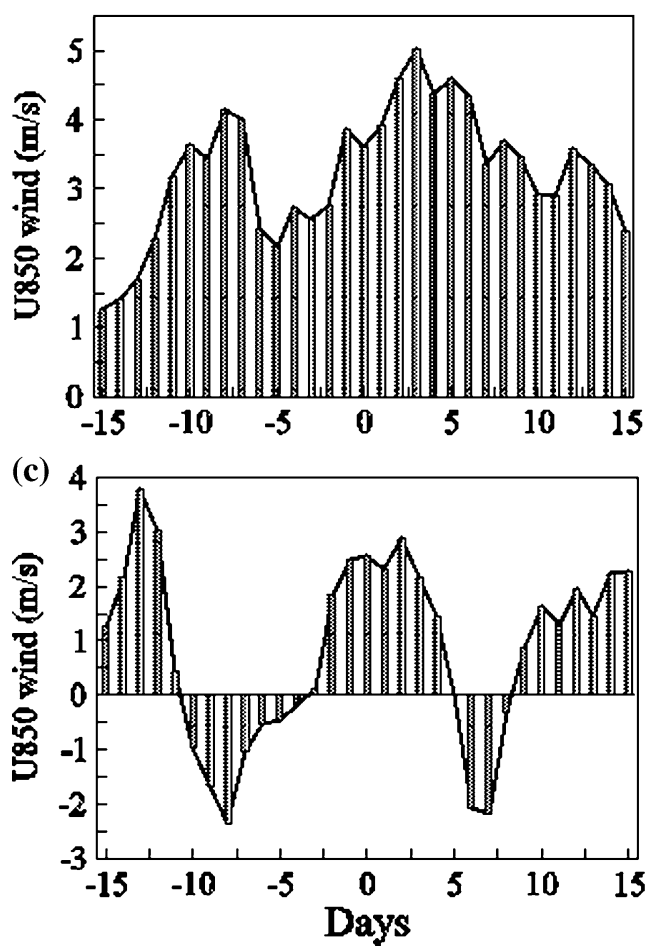

(b)

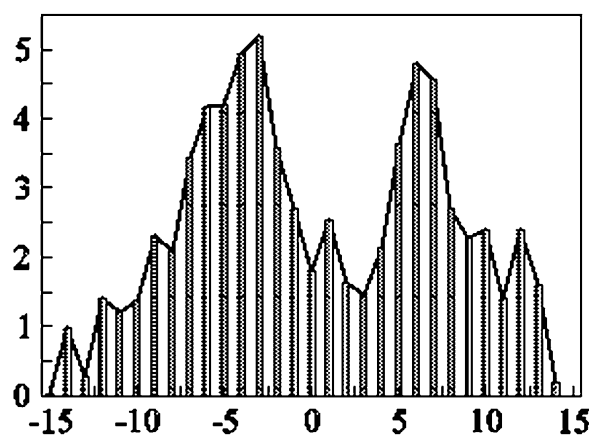

propagation. The longitudinal average $\left(70^{\circ}-90^{\circ} \mathrm{E}\right)$ of the anomalies shows a strong northward movement of suppressed convection anomalies. The analysis indicates that eastward propagating $\mathrm{MJO}$ is strong in the equatorial region during VLB, similar to the one present in winter; and this eastward propagating MJO seems to generate westward moving Rossby waves between $10^{\circ}$ and $25^{\circ} \mathrm{N}$. This is confirmed further using wavenumber-frequency spectrum analysis. This supports our hypothesis that during VLB, there exists an eastward propagating MJO in the equatorial Indian Ocean, which may give rise to a divergent field north of the equator. This divergent field may generate Rossby type of wave that moves northwestward towards the Indian region, leading to the sustenance of breaks.

Spectrum analysis carried out for winter, summer, drought and flood periods show that eastward propagating equatorial MJO is present in summer with a reduced magnitude, as compared to winter. Within the summer season, MJO is much stronger during drought years in comparison with that during flood years. On averaging the symmetric part of OLR spectrum over the wavenumber range 1-4 (the wavenumber over which MJO spans), the eastward power overrides westward power during drought, in the period 30-60 days, whereas westward power is comparable or larger than the eastward power during flood. This clearly supports that an eastward propagating MJO is stronger during drought years, in comparison with that during flood years.
Studies exemplify that air-sea interaction is pivotal in causing monsoon droughts. Here, we show that WWEs associated with MJO are predominant in the western Pacific. These WWEs can lead to the extension of warm SST anomalies to the east, initiating an El-Niño, as pointed out by Saith and Slingo (2006). However, there are many VLB during non El-Niño years as well. We find that during VLB, the warm pool of western Pacific extends to the central and eastern Pacific irrespective of existence or otherwise of an El-Niño. This extension of the warm pool to the east allows propagation of the MJO further eastwards and extends its period, causing breaks to sustain. Thus, airsea interaction on intraseasonal time scale is necessary and sufficient to cause VLB and ISM droughts. Air-sea interactions that sustain further, leading to interannual variability such as the ENSO, is helpful in producing VLB but not necessary.

As against monsoon droughts associated with El-Niño involving large scale low frequency ocean-atmosphere interaction and could be termed as 'externally' forced, the mechanism of monsoon droughts proposed here through VLBs could be termed as driven by 'internal' dynamics involving higher frequency ocean-atmosphere interaction on sub-seasonal time scale. The ocean-atmosphere interaction generates VLBs through preferential excitation of lower frequency eastward propagating ISO. Thus, a monsoon drought year differs from a normal or flood year by large scale conditions that favor such sub-seasonal air-sea interaction. 
Acknowledgments One of the authors, Susmitha Joseph, wishes to acknowledge the Council of Scientific and Industrial Research (CSIR) for financial support. Susmitha Joseph is also thankful to Dr. M. S. Madhusoodhanan for providing the code for space-time spectrum analysis and Dr. Matthew Wheeler for helpful discussions and suggestions. The authors are thankful to the two anonymous reviewers for their valuable comments.

\section{References}

Annamalai H, Slingo J (2001) Active/break cycles: diagnosis of the intraseasonal variability over the Asian summer monsoon. Clim Dyn 18:85-102

Annamalai H, Sperber KR (2005) Regional heat sources and the active and break phases of boreal summer intraseasonal (30-50 day) variability. J Atmos Sci 62:2726-2748

Duchon CE (1979) Lanczos fitering in one and two dimensions. J Appl Meteorol 18:1016-1022

Dunkerton TJ, Baldwin MP (1995) Observation of 3-6 day meridional wind oscillations over the tropical Pacific, 1973-1992: horizontal structure and propagation. J Atmos Sci 52:1585-1601

Gadgil S, Asha G (1992) Intraseasonal variation of the summer monsoon. I: Observational aspects. J Meteor Soc Japan 70:517527

Gadgil S, Joseph PV (2003) On breaks of the Indian monsoon. Proc Ind Acad Sci Earth Planet Sci 112:529-558

Goswami BN (1998) Interannual variation of Indian summer monsoon in a GCM: external conditions versus internal feedbacks. J Clim 11:501-522

Goswami BN (2005) South Asian Monsoon. In: Lau WKM, Waliser DE (eds) Intraseasonal variability in the atmosphere-ocean climate system, Chap. 2, pp 19-61

Goswami BN, Shukla J (1984) Quasi-periodic oscillations in a symmetric general circulation model. J Atmos Sci 41:20-37

Goswami BN, AjayaMohan RS (2001) Intraseasonal oscillations and interannual variability of the Indian summer monsoon. J Clim 14:1180-1198

Gruber A, Kruger AF (1984) The status of the NOAA outgoing longwave radiation dataset. Bull Am Meteor Soc 65:958-962

Kalnay E, co-authors (1996) The NCEP/NCAR 40-year reanalysis project. Bull Am Meteor Soc 77:437-471

Kemball-Cook S, Wang B (2001) Equatorial waves and air-sea interaction in the Boreal summer intraseasonal oscillation. J Clim 14:2923-2942

Kripalani RH, Kulkarni A, Sabade SS, Revadekar JV, Patwardhan SK, Kulkarni JR (2004) Intraseasonal oscillations during monsoon 2002 and 2003. Curr Sci 87:325-331

Krishnamurti TN, Ardanuy P (1980) The 10-20 day westward propagating mode and breaks in the monsoon. Tellus 32:15-26

Krishnamurti TN, Subrahmanyam D (1982) The 30-50-day mode at $850 \mathrm{mb}$ during MONEX. J Atmos Sci 39:2088-2095

Krishnan R, Zhang C, Sugi M (2000) Dynamics of breaks in the Indian summer monsoon. J Atmos Sci 57:1354-1372

Krishnan R, Mujumdar M, Vaidya V, Ramesh KV, Satyan V (2003) The abnormal Indian summer monsoon of 2000. J Clim 16:1177-1194

Krishnan R, Ramesh KV, Samala BK, Meyers G, Slingo JM (2006) Indian Ocean-monsoon coupled interactions and impending monsoon droughts. Geophys Res Lett 33:L08711. doi: 10.1029/2006GL025811

Kumar KK, Rajagopalan B, Hoerling M, Bates G, Cane M (2006) Unraveling the mystery of Indian monsoon failure during El-Niño. Science 314:115-119
Lau KM, Chan PH (1986) Aspects of the 40-50 day oscillation during the northern summer as inferred from outgoing longwave radiation. Mon Wea Rev 114:1354-1367

Lawrence DM, Webster PJ (2002) The boreal summer intraseasonal oscillation: relationship between northward and eastward movement of convection. J Atmos Sci 59:1593-1606

Madden RA, Julian PR (1971) Detection of a 40-50 day oscillation in the zonal wind in the tropical Pacific. J Atmos Sci 28:702-708

Madden RA, Julian PR (1972) Description of global-scale circulation cells in the tropics with a 40-50 day period. J Atmos Sci 29:1109-1123

Madden RA, Julian PR (1994) Observations of the 40-50-day tropical oscillations-a review. Mon Wea Rev 122:814-837

Mujumdar M, Kumar V, Krishnan R (2006) The Indian summer monsoon drought of 2002 and its linkage with tropical convective activity over northwest Pacific. Clim Dyn 28:743-758. doi: 10.1007/s00382-006-0208-7

Rajeevan M, Bhate J, Kale JD, Lal B (2006) High resolution daily gridded rainfall data for the Indian region: analysis of break and active monsoon spells. Curr Sci 91:296-306

Ramamurty K (1969) Some aspects of the "Break" in the Indian southwest monsoon during July and August. Forecasting manual FMU report No. IV-18.3

Raman CRV, Rao YP (1981) Blocking highs over Asia and monsoon droughts over India. Nature 289:221-223

Ramaswamy C (1962) Breaks in the Indian summer monsoon as a phenomenon of interaction between easterly and the subtropical westerly jet streams. Tellus 14:337-349

Rasmusson E, Carpenter T (1982) Variations in tropical sea surface temperature and surface wind fields associated with the Southern Oscillation/El-Niño. Mon Wea Rev 110:354-384

Reynolds RW, Rayner NA, Smith TM, Stokes DC, Wang W (2002) An improved in situ and satellite SST analysis for climate. J Clim 15:1609-1625

Rodwell MJ (1997) Breaks in the Asian monsoon: the influence of southern hemispheric weather systems. J Atmos Sci 54:25972611

Rui H, Wang B (1990) Development characteristics and dynamic structure of tropical intraseasonal convection anomalies. J Atmos Sci 47:357-379

Saith N, Slingo J (2006) The role of the Madden-Julian oscillation in the El-Niño and Indian drought of 2002. Int J Climatol 26:13611378

Sajani S, Beegum N, Krishna Moorthy K (2007) The role of lowfrequency intraseasonal oscillations in the anomalous Indian summer monsoon rainfall of 2002. J Earth Syst Sci 116:149-157

Salby ML, Hendon HH (1994) Intraseasonal behavior of winds, temperature and convection in the tropics. J Atmos Sci 52:22072224

Shukla J (1987) Interannual variability of monsoons. In: Fein JS, Stephens PL (eds) Monsoons, Chap. 14.

Sikka DR (1980) Some aspects of the large-scale fluctuations in the planetary and regional scale circulation parameters. Proc Ind Acad Sci Earth Planet Sci 89:179-195

Sikka DR, Gadgil S (1980) On the maximum cloud zone and the ITCZ over Indian longitudes during the southwest monsoon. Mon Wea Rev 108:1840-1853

Singh SV, Kripalani RH, Sikka DR (1992) Interannual variability of the Madden-Julian oscillations in Indian summer monsoon rainfall. J Clim 5:973-978

Smith TM, Reynolds RW (2004) Improved extended reconstruction of SST (1854-1997). J Clim 17:2466-2477

Uppala SM, Kallberg PW, Simmons AJ, Andrae U, a Bechtold V, Fiorino $\mathrm{M}$ et al (2005) The ERA-40 re-analysis. Quart J Roy Meteor Soc 131:2961-3012 
Walker GT, Bliss EW (1932) World weather. Mem R Meteorol Soc 4:53-84

Walker GT (1933) Seasonal weather and its prediction. Brit Assoc Adv Sci 103:25-44

Wang B (2005) Theory. In: Lau WKM, Waliser DE (eds) Intraseasonal variability in the atmosphere-ocean climate system, Chap. 10, pp 307-360.

Wang B, Rui H (1990) Synoptic climatology of transient tropical intraseasonal convection anomalies: 1975-1985. Meteorol Atmos Phys 44:43-61

Webster PJ, Yang S (1992) Monsoon and ENSO: selectively interactive systems. Quart J Roy Meteor Soc 118:877-926
Wheeler M, Kiladis GN (1999) Convectively coupled equatorial waves: analysis of clouds and temperature in the wavenumberfrequency domain. J Atmos Sci 56:374-399

Wu MC, Schubert SD, Suarez MJ, Pegion PJ, Waliser DE (2006) Seasonality and meridional propagation of MJO. J Clim 19:1901-1921

Xavier PK, Goswami BN (2007) A promising alternative to prediction of seasonal mean all India rainfall. Curr Sci 93:195202

Yasunari T (1980) A quasi-stationary appearance of 30-40 day period in cloudiness fluctuations during the summer monsoon over India. J Meteor Soc Japan 58:225-229 